\title{
BMJ Open Association between sleep duration and hypertension of migrant workers in China: a national cross-sectional surveillance study
}

\author{
Yunqi Guan (D) , ${ }^{1}$ Mei Zhang, ${ }^{1}$ Xiao Zhang, ${ }^{1}$ Zhenping Zhao, ${ }^{1}$ Zhengjing Huang, \\ Chun Li, ${ }^{1}$ Qian Xiao, ${ }^{2}$ Limin Wang ${ }^{1}$
}

To cite: Guan Y, Zhang M, Zhang $\mathrm{X}$, et al. Association between sleep duration and hypertension of migrant workers in China: a national cross-sectional surveillance study. BMJ Open 2019;9:e031126. doi:10.1136/ bmjopen-2019-031126

- Prepublication history and additional material for this paper are available online. To view these files, please visit the journal online (http://dx.doi. org/10.1136/bmjopen-2019031126).

Received 18 April 2019 Revised 24 October 2019 Accepted 28 0ctober 2019

\section{Check for updates}

(c) Author(s) (or their employer(s)) 2019. Re-use permitted under CC BY-NC. No commercial re-use. See rights and permissions. Published by BMJ.

${ }^{1}$ National Center for Chronic and Noncommunicable Disease Control and Prevention, Chinese Center for Disease Control and Prevention, Beijing, China ${ }^{2}$ Department of Health and Human Physiology and Department of Epidemiology, University of lowa, lowa City, Iowa, USA

\section{Correspondence to}

Dr Qian Xiao;

qian-xiao@uiowa.edu

Professor Limin Wang; wanglimin@ncncd.chinacdc.cn

\section{ABSTRACT}

Objectives To examine the relationship between sleep duration and hypertension of migrant workers aged 18-59 years in China.

Design Population-based cross-sectional study using a complex survey sampling design.

Participants There were 43655 subjects in our analysis, after excluding people with missing information for key exposure and outcome variables and abnormal values for sleep duration ( $\leq 2$ or $\geq 17$ hours).

Primary outcome measure Hypertension was defined as systolic blood pressure (BP) $\geq 140 \mathrm{~mm} \mathrm{Hg}$ and/or diastolic $\mathrm{BP} \geq 90 \mathrm{~mm} \mathrm{Hg}$, or self-reported history of hypertension diagnosis in hospitals at the township (community) level or above and use of hypertensive medicine in the last 2 weeks.

Results Of 43655 subjects, $15.6 \%$ (95\% Cl 15.1\% to $16.1 \%$ ) of migrant workers had hypertension. The prevalence of hypertension decreased with the increased sleep duration, both in males and females. Logistic regression models, using 7-8hours sleep/day as the reference, showed a greater odds for hypertension among men and women who reported $<6$ hours of sleep after adjusting for sociodemographic characteristics, behavioural risk factors, body mass index, diabetes, stroke and myocardial infarction (men: OR 1.26; 95\% Cl 1.03 to 1.54 , women: $\mathrm{OR} 1.55 ; 95 \% \mathrm{Cl} 1.13$ to 2.06 , $\left.\mathrm{p}_{\text {interaction }}=0.096\right)$. Further stratified by age and migration time, it revealed that among adults less than 45 years old, those sleeping 9 or more hours had adjusted odds for hypertension of 0.82 (95\% Cl 0.72 to 0.93 , $\mathrm{p}_{\text {interaction }}=0.020$ ), while there was no evidence of an association between sleep duration and hypertension among adults aged $45-59$ years. Among adults whose migration time was less than 4.5 years, those sleeping 9 or more hours had adjusted odds for hypertension of 0.80 $\left(95 \% \mathrm{Cl} 0.68\right.$ to $\left.0.94, \mathrm{p}_{\text {interaction }}=0.097\right)$.

Conclusion The association between sleep duration and hypertension varies by age. Short sleep duration ( $<6$ hours) is associated with an increased prevalence of hypertension in both genders.

\section{INTRODUCTION}

During the past few decades, the population of migrant workers in China continued to
Strengths and limitations of this study

- Our study addressed an important gap in the literature because no previous study has investigated the association between sleep duration and hypertension among migrant workers in China.

- The statistical analysis considered multistage occupational-stratified clustering sampling method and used proper sample weight, so the results are nationally representative.

- Due to the cross-sectional study design, this study could not determine the causal relationship between sleep duration and hypertension.

- We did not collect data on psychological stress and obstructive sleep apnoea, which may play a role in the relationship between sleep duration and hypertension.

grow from 211 million in 2009 to 236 million in 2012, representing more than a sixth of the nation's total population. ${ }^{1}$ Changes in living and working conditions as well as lifestyles (eg, physical activity, sleep and diet) caused by active migration are likely to affect the health of migrant workers. ${ }^{2}$ However, few studies have examined the relationships between modifiable risk factors and health outcomes in this population.

Epidemiological studies suggest that sleep deprivation and poor quality of sleep are associated with a number of health outcomes, including hypertension. ${ }^{3-6}$ According to the 2015 China Sleep Index Report, the average self-reported sleep time among Chinese is 8 hours and $12 \mathrm{~min}$. Studies that examined the relationship between sleep duration and hypertension have shown mixed results. ${ }^{7-12}$ For example, Stranges et al reported that shorter sleep duration was associated with higher risk of hypertension, which may in turn lead to detrimental cardiovascular effects among women. ${ }^{8}$ Nevertheless, Lima-Costa 


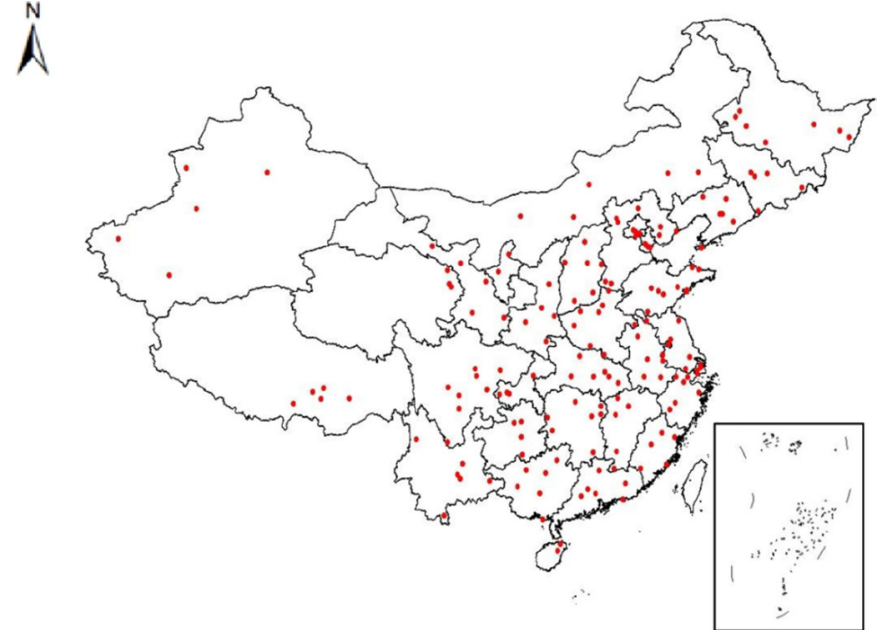

Figure 1 Map of 2012 China Non-communicable and Chronic Disease Risk Factor Surveillance Sites in migrant workers.

et al reported that sleep duration was not associated with hypertension in Brazilian elderly (60-95 years). ${ }^{10}$ Although the mechanisms underlying the varying association between sleep duration and hypertension and other cardiovascular outcomes are not fully understood, some studies indicate that the biological pathways may involve overactivity of sympathetic nerve and renin-angiotensinaldosterone system, ${ }^{13}{ }^{14}$ changes in circadian rhythms, ${ }^{15}$ hormone alterations ${ }^{16}$ and changes in the immune, metabolic and endocrine systems. ${ }^{1718}$

The relationship between sleep duration and hypertension in a nationally representative migrant workers in China has not been reported. Therefore, we conducted this study to investigate the association between selfreported sleep duration and the prevalence of hypertension using the data of the 2012 China Non-communicable Disease and Risk Factor Surveillance in migrant workers.

\section{METHODS}

\section{Study population}

Data were from the 2012 China Non-communicable and Chronic Disease Risk Factor Surveillance of migrant workers from 170 counties in all 31 provinces (including the 4 direct jurisdiction cities and 5 autonomous regions) and the Xinjiang production and construction corps in China. The geographical distribution of surveillance points is presented in figure 1. Migrant workers are defined as those who have lived for more than half a year for work in a town that is different from where the household Hukou (ie, the national household registration in China) was originally registered. ${ }^{2} 19$ The participants were 18-59 years old. Students, unemployed persons and visitors were excluded. The 2012 surveillance in migrant workers selected participants by using a multistage clustering sampling method, stratified by occupation. First, within the six major industry categories (ie, manufacturing industry, wholesale and retail trade industry, hospitality and food services industry, social service industry, construction industry and other industries), subindustry categories were selected according to the industry distribution characteristics of the survey area and the industry classification standard of the National Bureau of Statistics; second, within each subindustry category, two or three functional organisations were selected according to its scale using a simple random number allocation method; lastly, 50 available migrant workers from the eligible lists were selected in clusters from departments within each functional organisation until the predetermined sample size 51000 (300 participants in each county and there were 170 counties) according to the national report on migrant workers and the ratio between the resident population and the migrant workers was reached. ${ }^{20}$

Overall, there were 50209 subjects participated in the 2012 surveillance. After preliminary data cleaning (we excluded the participants whose questionnaire had logical error), the effective sample size was 48704 nationally. Of the 48704 subjects, 5049 subjects were excluded from the statistical analysis because of missing or abnormal values in key exposure and outcome variables including self-reported sleep time, self-reported hypertension and objectively measured systolic blood pressure (SBP) and diastolic blood pressure (DBP). Abnormal values referred to migrant workers whose self-reported sleep time was $\leq 2$ hours or $\geq 17$ hours. The final analytical sample included 43655 participants.

\section{Sleep duration}

Sleep duration was assessed by a self-reported questionnaire with the following question: 'How many hours do you usually sleep a day (including at night and naps) in the past 30 days?' Consistent with existing research, ${ }^{10-12}$ sleep duration was categorised into five categories: $<6$ hours, 6 (ie, $\geq 6$ and $<7$ hours), 7 (ie, $\geq 7$ and $<8$ hours), 8 (ie, $\geq 8$ and $<9$ hours), $\geq 9$ hours.

\section{Definition of hypertension}

Blood pressure was measured with an electronic sphygmomanometer (Omron HBP 1300) after the subjects had rested for $5 \mathrm{~min}$ in sitting position. SBP and DBP were measured three times with a $1 \mathrm{~min}$ interval. Three readings of SBP and DBP were recorded, and the average of the last two readings was used for data analysis. Hypertension was defined as $\mathrm{SBP} \geq 140$ or $\mathrm{DBP} \geq 90 \mathrm{~mm} \mathrm{Hg}$, or based on self-reported diagnosis of hypertension in hospitals at the township (community) level hospitals or above and had been taking medicine in the last 2 weeks.

\section{Covariates}

Information on sociodemographic characteristics (sex, age, education, income, inflow area, etc), behavioural risk factors for chronic diseases (smoking, alcohol consumption, physical activity, etc) and body mass index (BMI), diabetes, stroke and myocardial infarction were collected through a questionnaire by face-to-face interview with 
trained interviewers. As the effects of sleep duration on hypertension varied with age and duration of migration time, study participants were divided into two age groups: 18-44 and 45-59 years. ${ }^{20}$ Duration of migration time was categorised into two groups using a median split: $<4.5$ and $\geq 4.5$ years. China's Southern and Northern divisions are defined by the Huaihe River in the Qinling Mountains. Beijing, Tianjin, Hebei, Henan, Shanxi, Shaanxi, Shandong, Liaoning, Jilin, Heilongjiang, Qinghai, Gansu, Ningxia, Inner Mongolia and Xinjiang belong to the northern region. Shanghai, Chongqing, Jiangsu, Anhui, Hubei, Hunan, Guangdong, Guangxi, Zhejiang, Fujian, Jiangxi, Sichuan, Guizhou, Yunnan, Tibet and Hainan belong to the Southern region. According to the Guidelines for Prevention and Control of Overweight and Obesity in Adults in China, ${ }^{21}$ BMI was calculated by the clinically measured height and weight and was divided into three groups: underweight (BMI $<18.5 \mathrm{~kg}$ / $\mathrm{m}^{2}$ ), normal weight $\left(18.5 \leq \mathrm{BMI}<24 \mathrm{~kg} / \mathrm{m}^{2}\right)$, overweight and obesity (BMI $\geq 24 \mathrm{~kg} / \mathrm{m}^{2}$ ). According to the Dietary Guidelines for Chinese Residents, ${ }^{22}$ excessive drinking was defined as an average daily alcohol intake of at least $25 \mathrm{~g}$ for males and $15 \mathrm{~g}$ for females. According to WHO recommendation, insufficient intake of vegetables and fruits was defined as an average daily intake of vegetables and fruits combined of less than $400 \mathrm{~g} \cdot{ }^{23}$ According to the World Cancer Research Foundation standards, the cumulative intake of pork, beef and mutton $\geq 100 \mathrm{~g}$ / day was defined as excessive red meat intake. ${ }^{24}$ Participants with diabetes were defined as individuals who had fasting blood glucose $\geq 7.0 \mathrm{mmol} / \mathrm{L}$ and/or blood glucose $\geq 11.1 \mathrm{mmol} / \mathrm{L}$ in the oral glucose tolerance test-2 hours and/or have been diagnosed as diabetes by township (community) level hospitals or above. Stroke and myocardial infarction patients were defined as individuals who had been diagnosed by township (community) level hospitals or above. ${ }^{20}$

\section{Statistical analysis}

Due to the deviation of some important indicators (mainly age, sex and occupation) between the sample and the overall distribution caused by the sampling method, in order to make the results of the survey representative of migrant workers aged 18-59 in China, the results used the data of the dynamic monitoring of migrant workers in 2012 by the former National Population and Family Planning Commission as the basis for a postweighted adjustment. The Taylor series variance method was used to estimate the $95 \%$ CI of sampling error and rate; RaoScott $\chi^{2}$ tests were conducted to test for group differences in prevalence or percentage, and the logistic regression models were used to examine the trends for ordered categorical variables. Multivariable logistic regression models were employed to calculate the OR and 95\% CI for the likelihood of hypertension associated with shorter or longer duration of sleep comparing to the reference category of 7 hours stratified by age, sex and migration time, which were performed post hoc. Heterogeneity of
OR by sex, age and migration time were tested post hoc by adding to the model an interaction term with sleep duration. Model 1 was an unadjusted model. Model 2 was adjusted for sociodemographic characteristics (such as sex, age, migration time, marriage status, education level, occupation, annual income, inflow area, migration time, working hours) and behavioural risk factors for chronic diseases (such as total static behaviour time, smoking status, alcohol consumption, vegetable and fruit intake, red meat intake and BMI). On the basis of model 2, model 3 was adjusted for diabetes, stroke and myocardial infarction because these were comorbidity in hypertension and were important confounders. Complex survey design weights was applied to all statistical description and inferences to get nationally representative estimates. All statistical analyses were carried out using SAS V.9.4 (SAS Institute). All statistical tests were two tailed, and significance was defined as $\mathrm{p}<0.05$.

Patients and public involvement

There was no patient involvement in this study.

\section{RESULTS}

A total of 43655 valid samples were included in the analysis. The sleep duration of migrant workers was mainly concentrated in 8-9 and 7-8hours, accounting for $45.9 \%$ and $24.5 \%$, respectively. The characteristics of the study population for subgroups according to sleep duration were presented at table 1 . The proportion of subjects who slept for less than 6 hours was higher among those aged 45 or older when compared with younger subjects. With increased migration time and working time, the proportion of subjects with less than 6 hours of sleep increased, while the proportion of subjects with 9 or more hours of sleep decreased. With the increase of BMI and alcohol consumption, the proportion of subjects who slept for more than 9 hours decreased. There was no statistical difference in the intakes of vegetable and fruit and red meat across different groups of sleep duration.

In $2012,15.6 \%$ of migrant workers aged $18-59$ years had hypertension (20.4\% in men and $9.0 \%$ in women) (table 2). The prevalence of hypertension in both men and women increased with age. The prevalence of hypertension in migrant workers decreased with increased education level. Among different occupations, the highest prevalence of hypertension was observed in the construction industry $(21.6 \%)$. The prevalence of hypertension in the north was higher than that in the South $(18.7 \%$ in the North and $12.7 \%$ in the South). The prevalence of hypertension in both males and females increased with increased migration time. Higher prevalence of hypertension was also associated with overweight/obesity, smoking and excessive drinking in both males and females. These trends were consistent with those observed for SBP, DBP and pulse pressure (online supplementary tables S1-S3). Specifically, the prevalence of hypertension in overweight/obese migrant workers $(44.7 \%)$ was nearly 
Table 1 Different demographic characteristics of migrant workers in China across categories of sleep duration

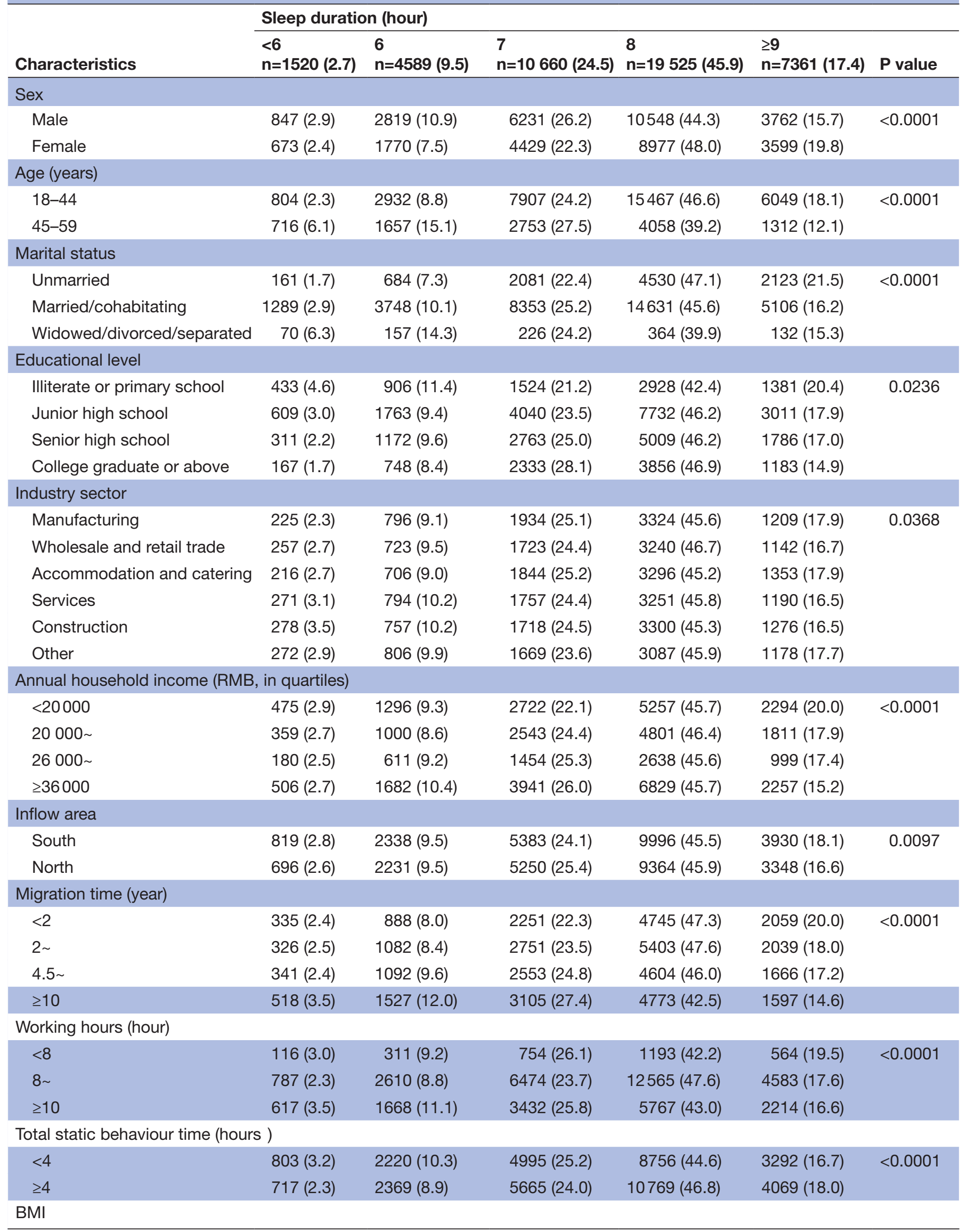


Table 1 Continued

\begin{tabular}{|c|c|c|c|c|c|c|}
\hline \multirow[b]{2}{*}{ Characteristics } & \multicolumn{6}{|c|}{ Sleep duration (hour) } \\
\hline & $\begin{array}{l}<6 \\
n=1520(2.7)\end{array}$ & $\begin{array}{l}6 \\
n=4589(9.5)\end{array}$ & $\begin{array}{l}7 \\
n=10660(24.5)\end{array}$ & $\begin{array}{l}8 \\
n=19525(45.9)\end{array}$ & $\begin{array}{l}\geq 9 \\
n=7361(17.4)\end{array}$ & $P$ value \\
\hline$<18.5$ & $1020(2.6)$ & 2907 (8.9) & $6918(23.7)$ & $13299(45.8)$ & $5418(19.0)$ & $<0.0001$ \\
\hline $18.5-23.9$ & $439(2.9)$ & $1432(10.4)$ & $3193(26.0)$ & $5413(46.3)$ & $1711(14.4)$ & \\
\hline$\geq 24$ & $61(2.6)$ & $250(12.6)$ & $549(28.5)$ & $813(43.8)$ & $232(12.5)$ & \\
\hline \multicolumn{7}{|l|}{ Smoking status } \\
\hline Non-current smoker & $985(2.4)$ & $2843(8.4)$ & $7123(23.9)$ & $13594(47.2)$ & $5142(18.1)$ & $<0.0001$ \\
\hline Current smoker & $535(3.3)$ & $1746(11.8)$ & $3537(25.8)$ & $5931(43.1)$ & $2219(16.0)$ & \\
\hline \multicolumn{7}{|c|}{ Alcohol consumption in the past 12 months } \\
\hline Never drinking & $761(2.5)$ & $2102(8.3)$ & $5018(22.5)$ & $10259(48.4)$ & $3785(18.3)$ & $<0.0001$ \\
\hline Drinking but not excessive & $525(2.5)$ & $1849(10.0)$ & $4500(26.5)$ & $7492(44.1)$ & $2912(16.9)$ & \\
\hline Excessive drinking & $234(4.8)$ & $638(13.7)$ & $1142(25.7)$ & $1774(40.9)$ & $664(14.9)$ & \\
\hline \multicolumn{7}{|l|}{ Vegetable and fruit intake } \\
\hline Insufficient intake & $642(2.6)$ & $2026(9.6)$ & $4783(25.0)$ & $8678(45.7)$ & $3162(17.1)$ & 0.1539 \\
\hline Adequate intake & $878(2.8)$ & $2563(9.4)$ & $5874(24.2)$ & $10845(46.0)$ & $4199(17.6)$ & \\
\hline \multicolumn{7}{|l|}{ Red meat intake } \\
\hline Normal intake & $680(2.8)$ & 2011 (9.6) & $4492(24.4)$ & $8077(45.6)$ & $3111(17.6)$ & 0.9821 \\
\hline Excessive intake & $840(2.6)$ & $2578(9.4)$ & $6168(24.7)$ & $11448(46.0)$ & $4250(17.3)$ & \\
\hline \multicolumn{7}{|l|}{ Hypertensive patients } \\
\hline Yes & 429 (3.9) & $1115(11.77)$ & $2066(26.04)$ & $3505(44.44)$ & $1117(13.85)$ & $<0.0001$ \\
\hline No & $1091(2.49)$ & $3474(9.10)$ & $8594(24.26)$ & $16020(46.09)$ & $6244(18.06)$ & \\
\hline \multicolumn{7}{|l|}{ Participants with diabetes } \\
\hline Yes & $53(4.7)$ & $130(15.5)$ & $208(23.2)$ & $344(42.4)$ & $99(14.2)$ & $<0.0001$ \\
\hline No & $1467(2.7)$ & $4459(9.4)$ & $10452(24.6)$ & $19181(45.9)$ & $7262(17.4)$ & \\
\hline \multicolumn{7}{|l|}{ Stroke patients } \\
\hline Yes & $13(9.9)$ & $13(13.7)$ & $22(24.6)$ & $32(40.1)$ & $12(11.7)$ & 0.0144 \\
\hline No & $1506(2.7)$ & $4569(9.5)$ & $10623(24.6)$ & $19465(45.8)$ & $7336(17.4)$ & \\
\hline \multicolumn{7}{|l|}{ Myocardial infarction patients } \\
\hline Yes & $8(14.8)$ & $7(9.5)$ & $11(19.1)$ & $20(44.8)$ & $13(11.8)$ & 0.0006 \\
\hline No & $1511(2.7)$ & 4575 (9.5) & $10634(24.6)$ & $19477(45.8)$ & 7335 (17.4) & \\
\hline
\end{tabular}

Data are expressed as $\mathrm{n}(\%)$. The percentages in table are row percent and were calculated with complex survey design weights. Rao-Scott $\chi^{2}$ tests were conducted to test for differences in percentage for unordered categorical variables and logistic regression models were used to examine the trends for ordered categorical variables.

BMI, body mass index.

twice as high as that in normal weight migrant workers $(20.8 \%)$. The prevalence of hypertension in excessive drinkers $(29.3 \%)$ was 2.3 times that in those who had never consumed alcohol $(12.7 \%)$.

Among migrant workers aged 18-59 years in China, the prevalence of hypertension decreased with increased sleep duration, both in males and females. Similar trends were also observed for SBP and DBP (online supplementary figures S1 and S2). The highest prevalence of hypertension was observed among those with less than 6 hours of sleep duration (26.4\% for men and $16.0 \%$ for women), while the lowest prevalence was observed among those reporting more than 9 hours of sleep (17.3\% for men and $7.1 \%$ for women) (figure 2). Figure 3 and online supplementary table S4 present adjusted ORs for the likelihood of having hypertension among subgroups defined by sex, age and migrant time across the five categories of sleep duration using 7-8 hours of sleep as the reference. Compared with the reference group, men and women who slept $<6$ hours a day had higher odds for hypertension (men: OR $1.27 ; 95 \%$ CI 1.04 to 1.56, women: OR 1.59; $95 \%$ CI 1.19 to 2.14 ), while those who slept $\geq 9$ hours a day had lower odds for hypertension in model 2 (men: OR $0.85 ; 95 \%$ CI 0.75 to 0.96 , women: OR $0.82 ; 95 \%$ CI 0.67 to 0.99 ). This trend persisted after additionally adjusting for diabetes, stroke and myocardial infarction in model 3. 


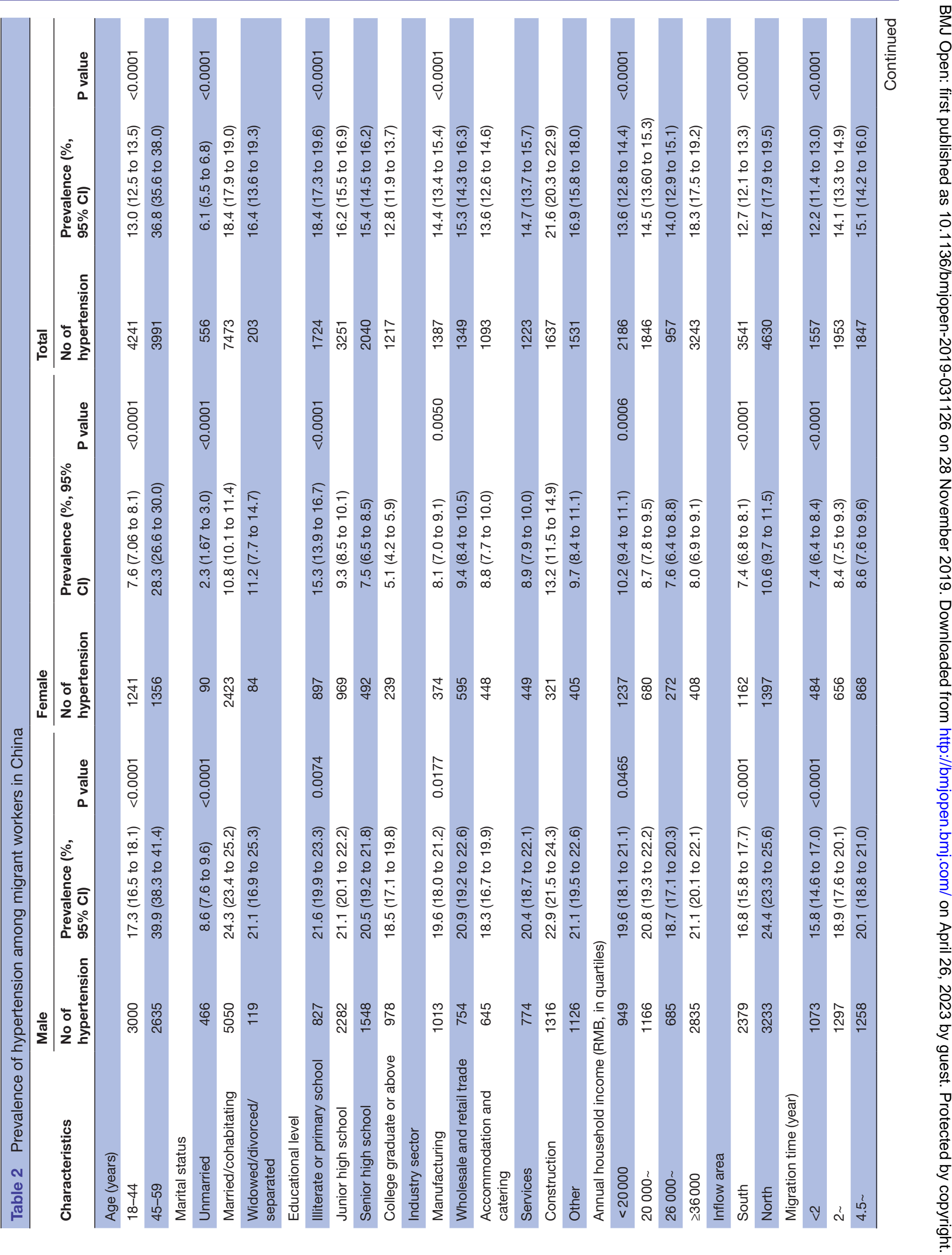




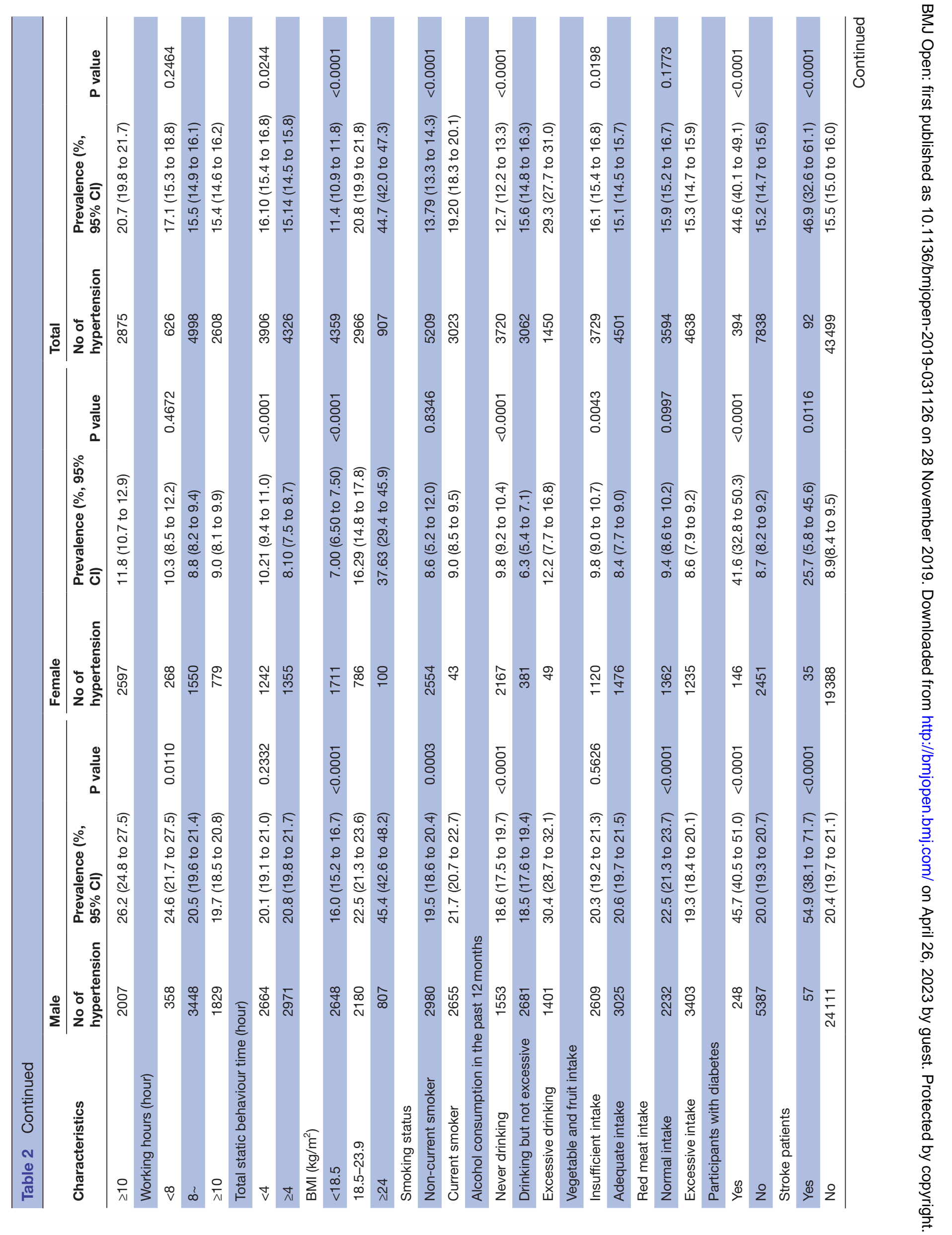




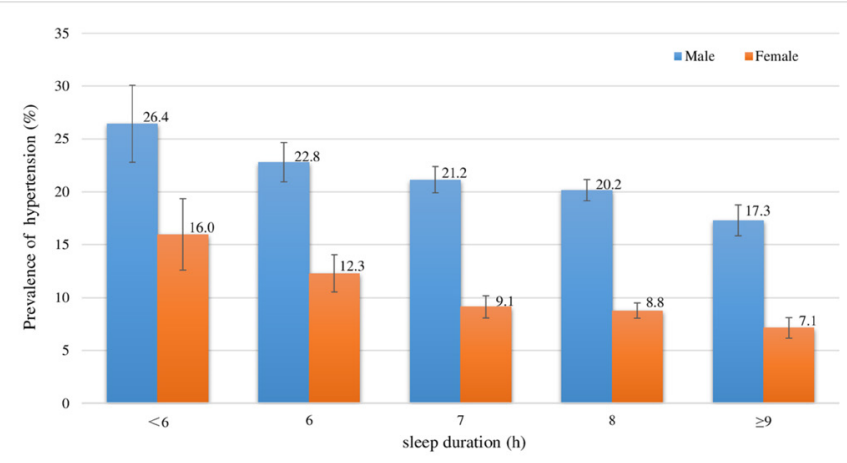

Figure 2 Prevalence $(95 \% \mathrm{Cl})$ of hypertension classified by sleep duration in different sex groups.

Among young adults aged 18-44 years, subjects who slept $\geq 9$ hours a day compared with those sleeping $7-8$ hours had lower odds of hypertension in model 2 and model 3 (model 2: OR 0.82; 95\% CI 0.71 to 0.92, model 3: OR 0.82 $95 \%$ CI 0.72 to 0.93$)$. However, in the older adults aged $\geq 45$ years, no significant association was found between sleep duration and hypertension in either model 2 or model 3. Among migrant workers whose migrant time $<4.5$ years, subjects who slept $\geq 9$ hours a day compared with those sleeping 7-8 hours had lower odds of hypertension in model 2 and model 3 (model 2: OR 0.75; 95\% CI 0.64 to 0.88 , model 3: OR $0.80 ; 95 \%$ CI 0.68 to 0.94 ). Subjects with migrant time $\geq 4.5$ years who slept $<6$ hours a day compared with those sleeping $7-8$ hours had greater odds of hypertension in model 2 and model 3 (model 2: OR 1.41; 95\% CI 1.14 to 1.76 , model 3: OR 1.29; $95 \%$ CI 1.01 to 1.61$)$.

\section{DISCUSSION}

This study found that $2.7 \%$ of migrant workers in China slept for less than 6 hours, $17.4 \%$ slept for 9 hours or more per day. Migrant workers who slept for less than 6 hours had higher odds for hypertension, while those who slept for more than 9 hours had lower odds for hypertension. There were also differences in the relationship between sleep duration and hypertension among participants with different gender, age and migration time. The odd for hypertension was 1.26 -fold (95\% CI 1.03 to 1.54) higher in men with short sleep duration $(<6$ hours $)$ than in those with a normal sleep duration (7-8hours) after adjusting for multiple confounders. Among women, less than 6 hours of sleep was associated with $55 \%$ increase in the odds of hypertension, compared with $26 \%$ increase in men, which suggested that the effects of short sleep on hypertension might be stronger among women than among men $\left(\mathrm{p}_{\text {interaction }}=0.096\right)$, and is consistent with several previous studies. For example, in a cross-sectional study of rural population in China, a sample of 1033 men and 783 women showed that hypertension was associated with short sleep duration in women. ${ }^{25}$ Results from the Whitehall II Cohort Study showed that compared with 


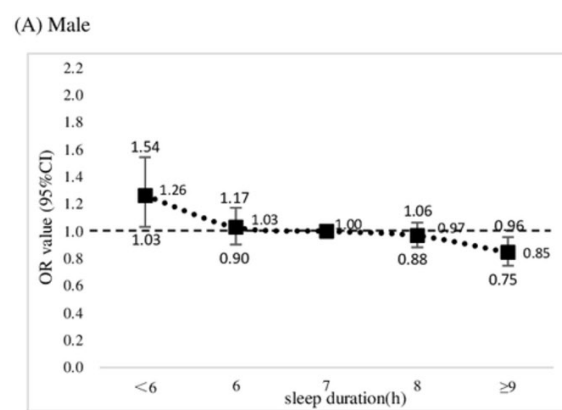

(B) Female

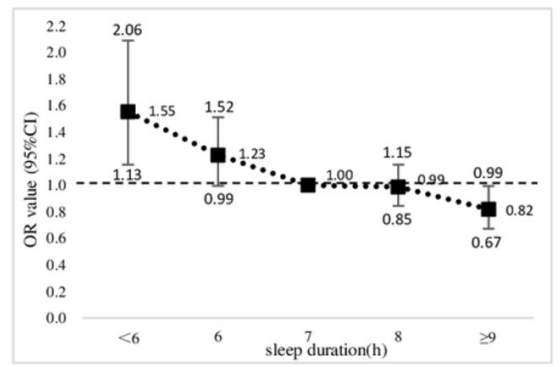

(C) 18-44 years old

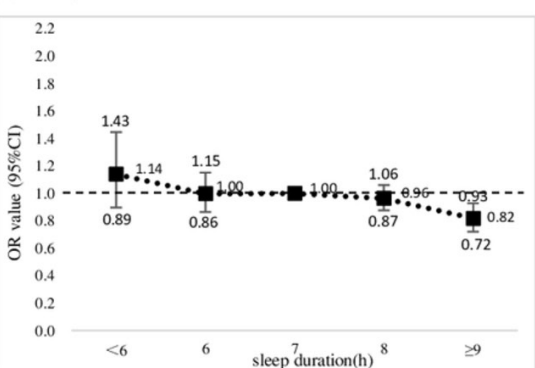

(D) 45-59 years old

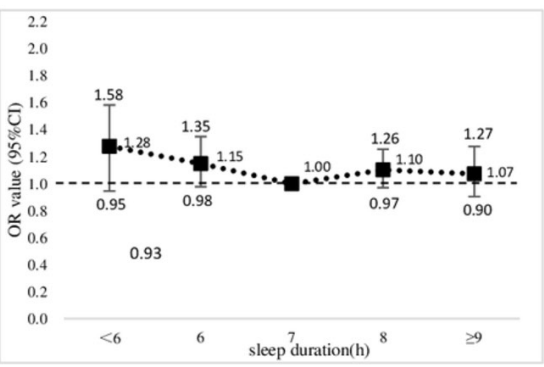

(E) Migration time $<4.5$ years

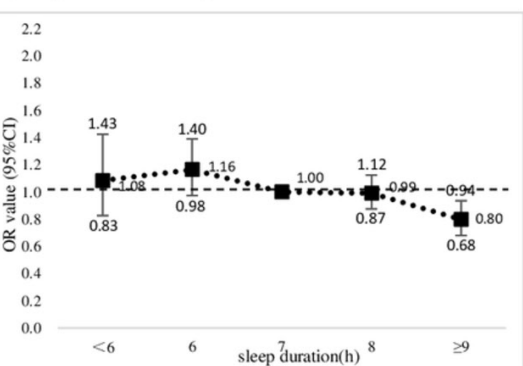

(F) Migration time $\geq 4.5$ years

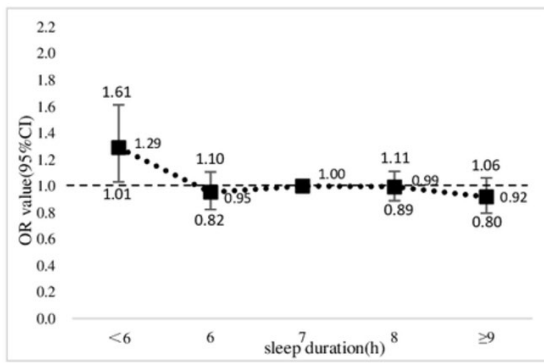

Figure 3 Association between sleep duration and hypertension in different subgroups. ORs in each group are presented as squares with $95 \% \mathrm{Cls}$ represented by extended lines. The horizontal reference line represents an OR value of ' 1 '. The dashed line represents the effects of different sleep durations on hypertension. (A) The male subgroup. (B) The female subgroup. (C) The 18-44 years old subgroup. (D) The 44-59years old subgroup. (E) The subgroup with migration time $<4.5$ years. (F) The subgroup with migration time $\geq 4.5$ years. Multivariable logistic model adjusted sex, age, migration time, marital status, education level, annual income, inflow area, working time, static behaviour time, red meat intake, smoking status, alcohol consumption, vegetable and fruit intake, $\mathrm{BMI}$, diabetes, stroke and myocardial infarction. BMI, body mass index.

7 hours of sleep, short duration of sleep ( 5 hours per night) was associated with a higher risk of hypertension among women with an inverse linear trend across decreasing hours of sleep while no association was detected in men. ${ }^{26}$ In a cross-sectional survey conducted among patients with hypertension in the hypertensive outpatient clinic of Anzhen Hospital and a community hospital in Beijing, China, researchers showed a modest association between short sleep duration and uncontrolled hypertension in middle-aged women but not in men. ${ }^{27}$ There may be two possible reasons that may explain the sex difference in the correlation between sleep duration and hypertension. The first reason is biological differences between women and men, including differences in genes and sex hormone levels. In particular, among perimenopausal and menopausal women, hormones fluctuate significantly, which may interact with sleep to influence blood pressure and lead to a stronger relationship between hypertension and short sleep duration in women than in men. ${ }^{25}$ Second, men and women have different family roles, educational levels, social pressures and accesses to healthcare. Stress has an important impact on cortisol level $^{28}$ and some studies have shown that when compared with men, women have a higher level of cortisol in the morning, ${ }^{29}$ which may affect the relationship between sleep duration and high blood pressure.

Among migrant workers aged 18-44 years, subjects with sleep duration more than 9 hours had lower odds for hypertension compared with those whose sleep duration was $7-8$ hours $\left(p_{\text {interaction }}=0.020\right)$, while there was no correlation between sleep duration and hypertension in those aged $45-59$ years $(\mathrm{p}>0.05)$. This finding was also consistent with those from previous studies. ${ }^{730}$ The pathogenesis of hypertension is different between younger and older adults. Hypertension in the middle aged and elderly is usually due to age-related arterial stiffness and increased peripheral resistance, while hypertension in the younger population is mainly caused by increased sympathetic activity and cardiac output. ${ }^{31}$ Sleep is related to sympathetic activity and cardiac output, ${ }^{32}$ which may partially explain the differences in the relationship between sleep duration and hypertension between the two age groups. Studies have shown that shorter sleep duration at night increases the risk of hypertension. ${ }^{33}$ Compared with young people, middleaged people have shorter sleep hours at night and have the habit of napping during the day, which may weaken the relationship between cumulative sleep duration and hypertension. Previous studies have found a significant association between daytime napping and hypertension and longer afternoon nap was associated with a higher increased risk of hypertension, ${ }^{34}{ }^{35}$ and Kallistratos et al found that midday sleep significantly decreased average day SBP/DBP in hypertensive people. ${ }^{36}$ The relationship and mechanisms between daytime napping and hypertension are not clearly demarcated and unfortunately, our study did not distinguish between daytime napping and nighttime sleep. Therefore, we were not able to evaluate 
the specific effect of daytime napping on hypertension definitely. In addition, the prevalence of chronic diseases such as hypertension, diabetes and obesity in middleaged people is usually higher than that of young people, and chronic diseases increase the total mortality rate of middle-aged people. ${ }^{37}$ Thus, survival bias may be another reason that sleep duration is unrelated to hypertension in middle-aged people.

With the increase of migration time, the prevalence of hypertension in migrant workers also increases, which may be related to the diminished healthy immigration effect. ${ }^{38}$ The health status of migrants is selectively better than other residents and general population in the emigration area $^{39}$ and the health advantages of immigrants disappear with increased years of residency. ${ }^{41}$ In our study, with the increase of migration time, the proportion of migrants who slept for less than 6 hours increased and the relationship between less than 6 hours of sleep and increased hypertension was stronger among people with a longer migration time $\left(\mathrm{p}_{\text {interaction }}=0.097\right)$. Our findings might reflect a cohort effect in which migrant workers with a longer migration time have a slightly stronger association between sleep duration and hypertension. Studies in migrant population have shown that health outcomes varied by length of migration time. ${ }^{42-44}$ However, the effect of different migration time on the association between sleep duration and hypertension has been rarely studied. Different environmental changes, living habits, acculturative stresses and illness burden faced by migrant workers with different migration time may explain these differences. ${ }^{45}$

Inconsistent with the 'U' pattern in other studies, ${ }^{12} 4647$ an inverse relation between sleep duration and hypertension was observed in our study, which was similar with the relationship between BMI and sleep duration. ${ }^{48} 49$ The inverse relation in our study may be due to the pressure on social integration, the types of jobs that migrant workers engage in and the public health services they enjoy, which are quite different from those of the permanent residents. ${ }^{50}$ Moreover, there were no hypothetical mechanisms for long sleep duration causing disease or death investigated either in the current paper or in other laboratory or epidemiological studies. $^{51}$

No study has examined the relationship between sleep duration and hypertension in migrant workers in China. Few Asian studies have reported on the relationship between sleep duration and hypertension. A Korean national cross-sectional study showed that short sleep duration ( $\leq 5$ hours) was independently associated with hypertension in young and middle-aged Korean adults but there was no association in those aged $\geq 65$ years. ${ }^{52}$ A cross-sectional analysis of the CARRS Study in Delhi, Chennai and Karachi in South Asia showed that there was no association between either short or long duration of sleep with hypertension after adjusting for other hypertension risk factors. ${ }^{53}$ A study conducted in Japanese male workers showed that sleep duration of 6 hours or more did not relate to the occurrence of any components of the metabolic syndrome, including hypertension. ${ }^{54}$ Different study results in Asia suggested that there was considerable variation in the relationship between duration of sleep and hypertension by gender, age groups and geographical regions. In this study, we analysed the relationship between sleep duration and hypertension in migrant workers of different gender, age groups as well as migration time, and adjusted various possible confounding factors. Therefore, it is of great significance to reflect the correlation between sleep duration and hypertension in China's migrant workers. It also provided some support for the previous research on biological mechanism and clues for further basic research.

This study has several limitations. First, data on psychological stress, obstructive sleep apnoea and sleep quality were not collected in this surveillance, while they may affect the association between sleep duration and hypertension. Studies found that obstructive sleep apnoea was an independent risk factor for hypertension and the risk for hypertension was synergistically increased in patients with both obstructive sleep apnoea and short sleep duration. ${ }^{55}$ The Penn State Cohort study found that chronic insomnia with short sleep duration was associated with an increased risk for incident hypertension and may be a premorbid modifiable risk factor for hypertension. ${ }^{57}$ These findings indicate that obstructive sleep apnoea and insomnia (especially in combination with short sleep) are confounders in the association between sleep duration and hypertension. However, due to lack of data on obstructive sleep apnoea and sleep quality, it is impossible to determine the impact of obstructive sleep apnoea and insomnia on the sleep duration of migrant workers. Second, our surveillance collected self-reported sleep duration, which is subjective to recall errors. Finally, this study is a cross-sectional study, so we could not determine the causal relationship between sleep duration and hypertension. We encourage future prospective studies to better evaluate a potential causal relationship between sleep duration and hypertension.

\section{CONCLUSION}

The results from this study suggest that the Chinese migrant workers who slept less than 6 hours had a higher prevalence of hypertension in both genders. However, the association was not found in the middle-aged population aged $45-59$ years. Further research is needed to investigate the biologic mechanisms that link sleep duration and hypertension and to explore the efficacy of sleep interventions for the treatment and prevention of hypertension in migrant workers.

Acknowledgements We thank Yiping Chen of Nuffield Department of Population Health, University of Oxford for the analysis suggestion and improved advice. We also thank all more than 300 research staffs from 31 provincial Centers for Disease 
Control and Prevention and 170 local Centers for Disease Control and Prevention for their collection of data and their efforts in quality control.

Contributors $Q X$ and $L W$ are joint corresponding authors. They contributed equally. YG conducted the statistical analysis and drafted the article. MZ gave support in statistical analysis and helped drafting the paper. XZ and ZZ involved in the data interpretation. ZH and CL contributed to the preparation of supplementary files. QX contributed to the revision of the manuscript. LW directed the study and contributed to the study conception and design. All authors approved the final manuscript.

Funding This study was supported by National Key Research and Development Program of Ministry of Science and Technology of the People's Republic of China (grant No.2018YFC1311706).

Map disclaimer The depiction of boundaries on this map does not imply the expression of any opinion whatsoever on the part of BMJ (or any member of its group) concerning the legal status of any country, territory, jurisdiction or area or of its authorities. This map is provided without any warranty of any kind, either express or implied.

\section{Competing interests None declared.}

Patient consent for publication Not required.

Ethics approval The study protocol was approved by the Ethical Review Committee of the Chinese Centre for Disease Control and Prevention.

Provenance and peer review Not commissioned; externally peer reviewed.

Data availability statement № data are available.

Open access This is an open access article distributed in accordance with the Creative Commons Attribution Non Commercial (CC BY-NC 4.0) license, which permits others to distribute, remix, adapt, build upon this work non-commercially, and license their derivative works on different terms, provided the original work is properly cited, appropriate credit is given, any changes made indicated, and the use is non-commercial. See: http://creativecommons.org/licenses/by-nc/4.0/.

\section{ORCID iD}

Yunqi Guan http://orcid.org/0000-0002-4012-7028

\section{REFERENCES}

1 National Bureau of Statistics of China. Statistical communiqué of the People's Republic of China on the 2012 national economic and social development. Beijing: National Bureau of Statistics of China,2013.[EB/OL].(2014-09-14). Available: http://www.stats.gov.cn/ english/NewsEvents/201302/ t20130222_26962.html

$2 \mathrm{Bi} \mathrm{Y}$, Wang L, Xu Y, et al. Diabetes-Related metabolic risk factors in internal migrant workers in China: a national surveillance study. Lancet Diabetes Endocrinol 2016;4:125-35.

3 Heslop P, Smith GD, Metcalfe C, et al. Sleep duration and mortality: the effect of short or long sleep duration on cardiovascular and all-cause mortality in working men and women. Sleep Med 2002;3:305-14.

4 García-Perdomo HA, Zapata-Copete J, Rojas-Cerón CA. Sleep duration and risk of all-cause mortality: a systematic review and meta-analysis. Epidemiol Psychiatr Sci 2019;28:578-88.

5 Ferrie JE, Shipley MJ, Cappuccio FP, et al. A prospective study of change in sleep duration: associations with mortality in the Whitehall II cohort. Sleep 2007;30:1659-66.

6 Gangwisch JE. A review of evidence for the link between sleep duration and hypertension. Am J Hypertens 2014;27:1235-42.

7 Lopez-Garcia E, Faubel R, Guallar-Castillon P, et al. Self-Reported sleep duration and hypertension in older Spanish adults. J Am Geriatr Soc 2009;57:663-8.

8 Stranges S, Dorn JM, Cappuccio FP, et al. A population-based study of reduced sleep duration and hypertension: the strongest association may be in premenopausal women. $J$ Hypertens 2010;28:896-902.

9 Bansil P, Kuklina EV, Merritt RK, et al. Associations between sleep disorders, sleep duration, quality of sleep, and hypertension: results from the National health and nutrition examination survey, 2005 to 2008. J Clin Hypertens 2011;13:739-43.

10 Lima-Costa MF, Peixoto SV, Rocha FL. Usual sleep duration is not associated with hypertension in Brazilian elderly: the Bambui health aging study (BHAS). Sleep Med 2008;9:806-7.

11 Magee CA, Kritharides L, Attia J, et al. Short and long sleep duration are associated with prevalent cardiovascular disease in Australian adults. J Sleep Res 2012;21:441-7.
12 Gottlieb DJ, Redline S, Nieto FJ, et al. Association of usual sleep duration with hypertension: the sleep heart health study. Sleep 2006;29:1009-14.

13 Tochikubo O, Ikeda A, Miyajima E, et al. Effects of insufficient sleep on blood pressure monitored by a new multibiomedical recorder. Hypertension 1996;27:1318-24.

14 Lusardi P, Zoppi A, Preti P, et al. Effects of insufficient sleep on blood pressure in hypertensive patients: a 24-h study. Am J Hypertens 1999;12:63-8.

15 Scheer FAJL, Van Montfrans GA, van Someren EJW, et al. Daily nighttime melatonin reduces blood pressure in male patients with essential hypertension. Hypertension 2004;43:192-7.

16 Spiegel K, Leproult R, Van Cauter E. Impact of sleep debt on metabolic and endocrine function. The Lancet 1999;354:1435-9.

17 Aldabal L, Bahammam AS. Metabolic, endocrine, and immune consequences of sleep deprivation. Open Respir Med $J$ 2011;5:31-43.

18 Irwin MR, Wang M, Ribeiro D, et al. Sleep loss activates cellular inflammatory signaling. Biol Psychiatry 2008;64:538-40.

19 Migrant Population Service Management Division of National Population and Family Planning Commission. Report on China's migrant population development 2010 (in Chinese). Beijing: China Population Publishing House, 2010.

20 National Center for Chronic and Noncommunicable Disease Control and Prevention, Chinese Center for Disease Control and Prevention. Report on Chronic Disease Risk Factor Survey Among Floating Population in China 2012 (in Chinese). Beijing: Military Medical Science Press, 2015.

21 Department of Disease Control and prevention of National Health Commission of the People's Republic of China. Guidelines for prevention and control of overweight and obesity in Chinese adults (in Chinese). Beijing: People's Medical Publishing House, 2006.

22 Department of Disease Control and prevention of National Health Commission of the People's Republic of China. Dietary Guidelines for Chinese Residents (2016) (in Chinese). Beijing: People's Medical Publishing House, 2016.

23 WHO. Global action plan for the prevention and control of noncommunicable diseases:2013-20.

24 World Cancer Research Fund International. Food, nutrition, physical activity and the prevention of cancer:a global perspective. Washington, DC: AICR, 2007.

25 Wang H, Zee P, Reid K, et al. Gender-Specific association of sleep duration with blood pressure in rural Chinese adults. Sleep Med 2011;12:693-9.

26 Cappuccio FP, Stranges S, Kandala N-B, et al. Gender-Specific associations of short sleep duration with prevalent and incident hypertension: the Whitehall II study. Hypertension 2007;50:693-700.

27 Zuo H, Wang J, Lin Y, et al. Gender-Specific associations of sleep duration with uncontrolled blood pressure in middle-aged patients. Clin Exp Hypertens 2016;38:125-30.

28 Han KS, Kim L, Shim I. Stress and sleep disorder. Exp Neurobiol 2012;21:141-50.

29 Pruessner JC, Gaab J, Hellhammer DH, et al. Increasing correlations between personality traits and cortisol stress responses obtained by data aggregation. Psychoneuroendocrinology 1997;22:615-25.

30 Fung MM, Peters K, Ancoli-Israel S, et al. Total sleep time and other sleep characteristics measured by actigraphy do not predict incident hypertension in a cohort of community-dwelling older men. $J$ Clin Sleep Med 2013;9:585-91.

31 Barlow SE. Expert Committee recommendations regarding the prevention, assessment, and treatment of child and adolescent overweight and obesity: summary report. Pediatrics 2007;120:S164-92.

32 Peach H, Gaultney JF, Reeve CL. Sleep characteristics, body mass index, and risk for hypertension in young adolescents. J Youth Adolesc 2015;44:271-84.

33 Wang Q, Xi B, Liu M, et al. Short sleep duration is associated with hypertension risk among adults: a systematic review and metaanalysis. Hypertens Res 2012;35:1012-8.

34 Cheungpasitporn W, Thongprayoon C, Srivali N, et al. The effects of napping on the risk of hypertension: a systematic review and metaanalysis. J Evid Based Med 2016:9:205-12.

35 Cao Z, Shen L, Wu J, et al. The effects of midday nap duration on the risk of hypertension in a middle-aged and older Chinese population. $J$ Hypertens 2014;32:1993-8.

36 Poulimenos L, Kallistratos M, Tsinivizov P, et al. Mid-day sleep effects as potent as recommended lifestyle changes in patients with arterial hypertension. J Am Coll Cardiol 2019;73:20.

37 Gangwisch JE, Heymsfield SB, Boden-Albala B, et al. Short sleep duration as a risk factor for hypertension. Hypertension 2006;47:833-9. 
38 McDonald JT, Kennedy S. Insights into the 'healthy immigrant effect': health status and health service use of immigrants to Canada. Soc Sci Med 2004;59:1613-27.

39 Jasso G, Massey D, Rosenzweig M, et al. Immigrant health: selectivity and acculturation 2004:48.

40 Antecol H, Bedard K. Unhealthy assimilation: why do immigrants converge to American health status levels? Demography 2006;43:337-60.

41 Shah SM, Loney T, Dhaheri SA, et al. Association between acculturation, obesity and cardiovascular risk factors among male South Asian migrants in the United Arab Emirates - a cross-sectional study. BMC Public Health 2015;15:1-11.

42 Norredam M, Agyemang C, Hoejbjerg Hansen OK, et al. Duration of residence and disease occurrence among refugees and family reunited immigrants: test of the 'healthy migrant effect' hypothesis. Trop Med Int Health 2014;19:958-67.

43 Urquia ML, Frank JW, Moineddin R, et al. Immigrants' duration of residence and adverse birth outcomes: a population-based study. BJOG 2010;117:591-601.

44 Goel MSet al. Obesity among US immigrant subgroups by duration of residence. JAMA 2004;292:2860-7.

45 Maneze D, Salamonson Y, Attwood N, et al. Acculturative stress in Filipino migrants with functional English: implications for health promotion. Int J Cult Ment Health 2014;7:357-69.

46 Fang J, Wheaton AG, Keenan NL, et al. Association of sleep duration and hypertension among US adults varies by age and sex. Am J Hypertens 2012;25:335-41.

47 Kuciene R, Dulskiene V. Associations of short sleep duration with prehypertension and hypertension among Lithuanian children and adolescents: a cross-sectional study. BMC Public Health $2014 ; 14: 255$.
48 Ford ES, Li C, Wheaton AG, et al. Sleep duration and body mass index and waist circumference among U.S. adults. Obesity 2014;22:598-607.

49 St-Onge M-P, Perumean-Chaney S, Desmond R, et al. Gender differences in the association between sleep duration and body composition: the cardia study. Int J Endocrinol 2010;2010:1-8.

50 Department of Floating Population, National Health and Family Planning Commission. Report on China's migrant population development 2015 (in Chinese). Beijing: China Population Publishing House, 2015.

51 Knutson KL, Turek FW. The U-shaped association between sleep and health: the 2 peaks do not mean the same thing. Sleep 2006;29:878-9.

$52 \mathrm{Kim}$ J, Jo I. Age-Dependent association between sleep duration and hypertension in the adult Korean population. Am J Hypertens 2010;23:1286-91.

53 Shivashankar R, Kondal D, Ali MK, et al. Associations of sleep duration and disturbances with hypertension in metropolitan cities of Delhi, Chennai, and karachi in South Asia: cross-sectional analysis of the CARRS study. Sleep 2017;40:1-10.

54 Kawada T, Okada K, Amezawa M. Components of the metabolic syndrome and lifestyle factors in Japanese male workers. Metab Syndr Relat Disord 2008;6:263-6.

55 Cano-Pumarega I, Durán-Cantolla J, Aizpuru F, et al. Obstructive sleep apnea and systemic hypertension: longitudinal study in the general population: the Vitoria sleep cohort. Am J Respir Crit Care Med 2011;184:1299-304.

56 Priou P, Le Vaillant M, Meslier N, et al. Cumulative association of obstructive sleep apnea severity and short sleep duration with the risk for hypertension. PLoS One 2014;9:e115666.

57 Fernandez-Mendoza J, Vgontzas AN, Liao D, et al. Insomnia with objective short sleep duration and incident hypertension: the Penn state cohort. Hypertension 2012;60:929-35. 